\title{
Comparison of chemical risk assessment methods in South Korea and the United Kingdom
}

\author{
Min-Uk KIM, Saemi ShIN and Sang-Hoon Byeon \\ Department of Health Science, Graduate School, Korea University, Republic of Korea
}

\begin{abstract}
Comparison of chemical risk assessment methods in South Korea and the United Kingdom: Min-Uk Kıм, et al. Department of Health Science, Graduate School, Korea University, Republic of Korea-Objectives: The objective of this study was to compare Control of Substances Hazard to Health (COSHH) Essentials (a chemical risk assessment method in the UK) with Chemical Hazard Risk Management (CHARM) (a chemical risk assessment method in South Korea). The differences between the two processes were explored with a particular focus on their features and distinctions. Methods: The results obtained from applying COSHH Essentials and CHARM to 59 carcinogenic, mutagenic, and reprotoxic (CMR) substances were analyzed. The outcomes of the working environment assessments and the collated information about the usage of CMR chemicals were used for the analysis. Results: Among the 59 substances tested, 56 substances were rated at a risk level lower than 2, when evaluated with CHARM. However, with $\mathrm{COSHH}$, all 59 substances were rated at risk level 3 or higher. With COSHH Essentials, the highest hazard group of 4 was automatically assigned to category $E$ substances, regardless of the exposure level assessment. However, for CHARM, the risk could be adjusted according to the exposure level assessment, even for hazard group of 4 . Conclusions: CHARM allocated lower risk levels to hazardous substances than $\mathrm{COSHH}$ Essentials. Ultimately, COSHH Essentials assesses exposure level through the physical properties and overall handling, and considers hazard with $\mathrm{H}$-statements and R-phrases. COSHH Essentials was deemed more conservative than CHARM. CHARM may have underestimated the risk according to exposure level, even though the chemicals were highly hazardous. Therefore, CHARM can be used for the localized risk assessment of chemicals used in individual workplaces.
\end{abstract}

(J Occup Health 2015; 57: 339-345)

Received Nov 9, 2014; Accepted Mar 12, 2015

Published online in J-STAGE Apr 17, 2015

Correspondence to: S.-H. Byeon, 145, Anam-ro, Seongbuk-gu, Seoul, 136-701, Republic of Korea (e-mail: shbyeon@korea.ac.kr)
Key words: Chemical Hazard Risk Management (CHARM), Carcinogenic, mutagenic, and reprotoxic (CMR), Control of Substances Hazard to Health (COSHH) Essentials, Exposure, Hazardous chemicals, Risk assessment

In South Korea, there is growing concern that chemical accidents are causing severe pollution and health problems ${ }^{1)}$. This is principally due to the continuous rise in the number of injuries and fatalities, alongside significant economic losses. There have recently been a number of chemical accidents, for example, hydrofluoric acid leakages in Gumi in 2012, at the Cheongju industrial complex in 2013, and at Samsung Electronics' Hwaseong workplace in $2013^{2)}$. It has become increasingly apparent that the government and employers have a responsibility to safeguard the health of their workers by ensuring that all chemicals are managed safely.

Examples of the existing risk assessment legislation include the Framework Directive on Safety and Health at Work (Directive 89/391/EEC, Europe), the Occupational Safety and Health Act 2006 (Japan), and the Workplace Safety and Health Act 2006 (Singapore) $)^{3)}$.

In 1998, the UK Health and Safety Executive (HSE) announced a series of papers concerning the control banding (CB) strategy used to determine the recommended level of risk control ${ }^{4}$. The HSE also developed the Control of Substances Hazardous to Health (COSHH) Essentials to give small- and medium-sized enterprises advice on approaches for conducting risk assessment of chemicals in the workplace ${ }^{5}$. $\mathrm{COSHH}$ Essentials is a global chemical-managing toolkit that uses warning labels and a simple method for predicting exposure ${ }^{6)}$. It employs a qualitative method based on the $\mathrm{CB}$ technique to assess and manage risks ${ }^{7}$. Various studies have been conducted using $\mathrm{COSHH}$ Essentials, which include a study on control methods and technique selection for vapor degreasing and bag filling operations and a study on comparing real 
exposure and control methods of organic chemicals in medium-sized businesses that produce coating and painting materials for automobiles ${ }^{8-12}$.

Protecting the health of workers from the effects of chemicals is challenging in South Korea. This is because business owners are required to limit the exposure of their workers to hazardous chemicals, but there is no formal chemical risk assessment process in place. In 2012, the Korea Occupational Safety and Health Agency (KOSHA) developed a chemical risk assessment system known as Chemical Hazard Risk Management (CHARM), which uses $\mathrm{CB}^{13)}$. Although CHARM has been referenced in academic, technical, and preliminary studies, its use as a form of risk assessment for protecting workers from exposure to hazardous chemicals has received minimal attention.

In order to address this issue, this study compares the COSHH Essentials (UK) risk assessment with the CHARM system (South Korea). The assessment of 59 carcinogenic, mutagenic, and reprotoxic (CMR) substances was performed using both processes, enabling direct comparison of the results according to exposure levels and usage quantities of the chemicals. From the results, the features and differences of the two systems were highlighted.

\section{Methods}

\section{COSHH essentials and CHARM}

For COSHH Essentials, R-phrases and H-statements are involved in hazard level assessment ${ }^{14)}$. Conversely, for CHARM, four sources of information are used to identify the following: (i) whether the chemical is a CMR substance, (ii) what the occupational exposure limit (TWA-OELs) is and (iii) what the R-phrases and $\mathrm{H}$-statements are according to the material safety data sheet $^{13)}$.

COSHH Essentials determines how much of the substance will be used according to its physical properties (e.g., dustiness and volatility) ${ }^{15}$. However, CHARM uses three assessment criteria, which include (i) considering whether the chemical has caused occupational diseases in works and then considering the occupational exposure levels, (ii) the quantities used, and (iii) the physical properties of the substance under consideration $^{13)}$.

For COSHH Essentials, there are five hazard groups ( $\mathrm{A}=$ very low, $\mathrm{B}=$ low, $\mathrm{C}=$ medium, $\mathrm{D}=$ high, $\mathrm{E}=$ very high) and four exposure levels (1=low, 2=medium, $3=$ high, 4=very high) for the risk assessment of chemicals; in the CHARM system, there are four hazard groups (1=low, 2=medium, 3=high, 4=very high) and four exposure levels (1=low, 2=medium, $3=$ high, 4=very high $)^{13,14)}$. The hazard definitions of COSHH Essentials and CHARM are identically classified according to the standards presented in "the Chemicals Hazard Information and Packaging for Supply Regulations" (CHIP) ${ }^{16)}$ and "Classification, Labeling, and Packaging of Substances and Mixtures Regulations" $(\mathrm{CLP})^{17)}$. However, there is a difference in the hazard groups that determine the hazard level, with one having five groups (A-E) and the other only four (1-4). In COSHH Essentials, CMR substances are classified as grades D-E if they are carcinogenic or mutagenic and as grade D if they are toxic for reproduction. On the other hand, in CHARM, CMR substances are not classified as grades D-E but are classified identically as grade 4, the highest hazard group. In COSHH Essentials and CHARM, the exposure definition is identically classified according to the physical properties (e.g., dustiness and volatility $)^{15)}$. However, in CHARM, when the results of working environment measurements are applied, the exposure levels are determined according to the exposure grades of the chemical substances (the results of the working environment measurements divided by the TWA-OELs), and there are four exposure levels (1=less than $10 \%, 2=10 \%$ or more but less than $50 \%, 3=50 \%$ or more but less than $100 \%$, $4=$ more than $100 \%)^{13)}$.

With CHARM, the final risk level (1=low, 2=medium, $3=$ high, $4=$ =ery high) is determined by classifying the results, which are obtained by multiplying the exposure level grade and the hazard score as shown in Table $1^{13)}$. However, for COSHH Essentials, the risk level is determined by combining the exposure level and hazard grades according to the physical state of the chemicals (e.g., solid or liquid) as shown in Fig. ${ }^{18)}$. Figure 1 shows a method for determining the risk level of COSHH Essentials and CHARM.

Table 1. Determination of the risk level for CHARM

\begin{tabular}{|c|c|c|c|c|}
\hline Hazard & 1 & 2 & 3 & 4 \\
\hline 1 & 1 & 2 & 3 & 4 \\
\hline 2 & 2 & 4 & 6 & 8 \\
\hline 3 & 3 & 6 & 9 & 12 \\
\hline 4 & 4 & 8 & 12 & 16 \\
\hline
\end{tabular}

\begin{tabular}{ccc}
\hline $\begin{array}{c}\text { Calculated } \\
\text { risk }\end{array}$ & $\begin{array}{c}\text { Risk } \\
\text { level }\end{array}$ & $\begin{array}{c}\text { Risk } \\
\text { information }\end{array}$ \\
\hline 1,2 & 1 & Low risk \\
3,4 & 2 & Medium risk \\
$6,8,9$ & 3 & High risk \\
12,16 & 4 & Very high risk \\
\hline
\end{tabular}

CHARM: Chemical Hazard Risk Management. 
(a) COSHH Essentials

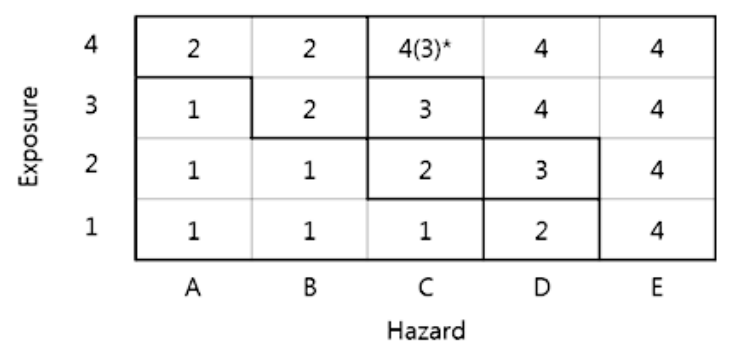

(b) CHARM

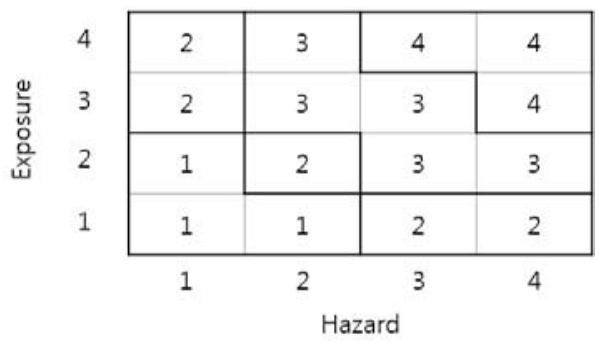

*(3): Risk level of liquid for COSHH Essentials

Fig. 1. Estimation of the risk level for Control of Substances Hazard to Health (COSHH) essentials and Chemical Hazard Risk Management (CHARM).
Application to hazardous substances

In accordance with the South Korean Occupational Safety and Health Acts, working conditions are investigated every 5 years ${ }^{19}$. Therefore, data involving annual chemical usage, number of exposed workers, and workplaces that use chemicals were obtained from these surveys.

In South Korea, the classification and concentration of hazardous airborne substances inhaled by workers is monitored, alongside any possible links to health issues. The workplace is then examined to determine whether improvements to working practices are required ${ }^{18)}$.

According to local occupational safety and health standard rules, hazardous substances that must be managed and monitored in working environments, include 113 organic compounds, 23 metals, 17 acids and alkalis, and 15 gaseous materials, and CMR substances are included in this group ${ }^{20)}$.

In this study, 59 chemicals for which both working environment measurements and usage information were available were used to compare the risk assessment methods of CHARM and COSHH Essentials ${ }^{21}$.

Table 2 shows the details of 17 chemical substances (a subgroup of the 59 chemicals studied), including hexane, methoxyethanol, etc. Daily usage was calculated by dividing the annual usage by the number of

Table 2. Chemical information

\begin{tabular}{cccccccc}
\hline Substance & CAS No. & $\begin{array}{c}\text { No. of } \\
\text { worker's }\end{array}$ & $\begin{array}{c}\text { No. of } \\
\text { workplaces }\end{array}$ & $\begin{array}{c}\text { TWA-OELs } \\
\left(\mathrm{mg} / \mathrm{m}^{3}\right)\end{array}$ & $\begin{array}{c}\text { Work } \\
\text { environment } \\
\text { measurements } \\
\left(\mathrm{mg} / \mathrm{m}^{3}\right)\end{array}$ & $\begin{array}{c}\text { Daily } \\
\text { amounts } \\
(\mathrm{t})\end{array}$ & $\begin{array}{c}\text { Daily } \\
\text { amounts (t) } \\
/ \\
\text { Workplaces }\end{array}$ \\
\hline 2,3-Epoxy-1-propanol & $556-52-5$ & 6 & 8 & 6.1 & 0.003 & $1 \times 10^{-5}$ & $1 \times 10^{-6}$ \\
Stoddard solvent & $8052-41-3$ & 885 & 16 & 525 & 14.8 & $1.35 \times 10^{2}$ & 8.44 \\
1,2,3-Trichloropropane & $96-18-4$ & 6 & 552 & 60 & 4.54 & 0.8 & $1.5 \times 10^{-3}$ \\
N,N-Dimethylacetamide & $127-19-5$ & 81 & 24 & 35 & 2.21 & $6.08 \times 10^{3}$ & $2.53 \times 10^{2}$ \\
Ethylene dichloride & $107-06-2$ & 161 & 1 & 40 & 1.61 & $4.98 \times 10^{3}$ & $4.98 \times 10^{3}$ \\
Acrylonitrile & $107-13-1$ & 283 & 2,522 & 4.5 & 0.07 & $2.25 \times 10^{3}$ & 0.89 \\
2-Methoxyethyl acetate & $110-49-6$ & 181 & 58 & 24 & 0.44 & 1.9 & $3.3 \times 10^{-2}$ \\
1,2-Epoxypropane & $75-56-9$ & 56 & 3 & 5 & 0.12 & 0.19 & 0.06 \\
Hexane (n-hexane) & $110-54-3$ & 3,336 & 11 & 180 & 2.72 & $1.15 \times 10^{4}$ & $1.05 \times 10^{3}$ \\
1,4-Dioxane & $123-91-1$ & 30 & 1 & 72 & 0.88 & 8.4 & 8.4 \\
Dichloromethane & $75-09-2$ & 2,116 & 106 & 175 & 10.42 & $5.57 \times 10^{3}$ & 52.57 \\
Hydroquinone & $123-31-9$ & 484 & 770 & 2 & 0.001 & 0.02 & $3 \times 10^{-5}$ \\
1,1,2-Trichloroethane & $79-00-5$ & 172 & 13 & 55 & 0.83 & 1.63 & 0.13 \\
Methyl n-butyl ketone & $591-78-6$ & 34 & 1 & 20 & 1.58 & 0.23 & 0.23 \\
Methoxyethanol & $109-86-4$ & 118 & 484 & 16 & 0.73 & 9.5 & 0.02 \\
$p$-Nitrochlorobenzene & $100-00-5$ & 3 & 114 & 0.6 & 0.001 & $1 \times 10^{-5}$ & $3 \times 10^{-7}$ \\
Vanadium pentoxide & $1314-62-1$ & 4 & 9 & 0.05 & 0.006 & 0.4 & 0.04 \\
\hline & & & & & & &
\end{tabular}


Table 3. Risk levels of CHARM and COSHH essentials

\begin{tabular}{|c|c|c|c|c|c|c|c|}
\hline \multirow{2}{*}{ Substance } & \multirow{2}{*}{ CAS NO. } & \multicolumn{3}{|c|}{ CHARM } & \multicolumn{3}{|c|}{ COSHH essentials } \\
\hline & & Hazard & Exposure & Risk level & Hazard & Exposure & Risk level \\
\hline 2,3-Epoxy-1-propanol & $556-52-5$ & 4 & 1 & 2 & $\mathrm{E}$ & 1 & 4 \\
\hline Stoddard solvent & $8052-41-3$ & 4 & 1 & 2 & $\mathrm{E}$ & 2 & 4 \\
\hline 1,2,3-Trichloropropane & $96-18-4$ & 4 & 1 & 2 & $\mathrm{E}$ & 2 & 4 \\
\hline N,N-Dimethylacetamide & $127-19-5$ & 4 & 1 & 2 & $\mathrm{D}$ & 2 & 3 \\
\hline Ethylene dichloride & $107-06-2$ & 4 & 1 & 2 & $\mathrm{E}$ & 3 & 4 \\
\hline Acrylonitrile & $107-13-1$ & 4 & 1 & 2 & $\mathrm{E}$ & 3 & 4 \\
\hline 2-Methoxyethyl acetate & $110-49-6$ & 4 & 1 & 2 & $\mathrm{D}$ & 3 & 4 \\
\hline 1,2-Epoxypropane & $75-56-9$ & 4 & 1 & 2 & $\mathrm{E}$ & 3 & 4 \\
\hline Hexane (n-hexane) & $110-54-3$ & 4 & 1 & 2 & $\mathrm{D}$ & 3 & 4 \\
\hline 1,4-Dioxane & $123-91-1$ & 4 & 1 & 2 & $\mathrm{D}$ & 3 & 4 \\
\hline Dichloromethane & $75-09-2$ & 4 & 1 & 2 & $\mathrm{D}$ & 4 & 4 \\
\hline Hydroquinone & $123-31-9$ & 4 & 1 & 2 & $\mathrm{E}$ & 1 & 4 \\
\hline 1,1,2-Trichloroethane & $79-00-5$ & 4 & 1 & 2 & $\mathrm{D}$ & 3 & 4 \\
\hline Methyl n-butyl ketone & $591-78-6$ & 4 & 1 & 2 & $\mathrm{D}$ & 3 & 4 \\
\hline Methoxyethanol & $109-86-4$ & 4 & 1 & 2 & $\mathrm{D}$ & 3 & 4 \\
\hline$p$-Nitrochlorobenzene & $100-00-5$ & 4 & 1 & 2 & $\mathrm{E}$ & 1 & 4 \\
\hline Vanadium pentoxide & $1314-62-1$ & 4 & 2 & 3 & $\mathrm{E}$ & 3 & 4 \\
\hline
\end{tabular}

CHARM: Chemical Hazard Risk Management. COSHH: Control of Substances Hazard to Health.
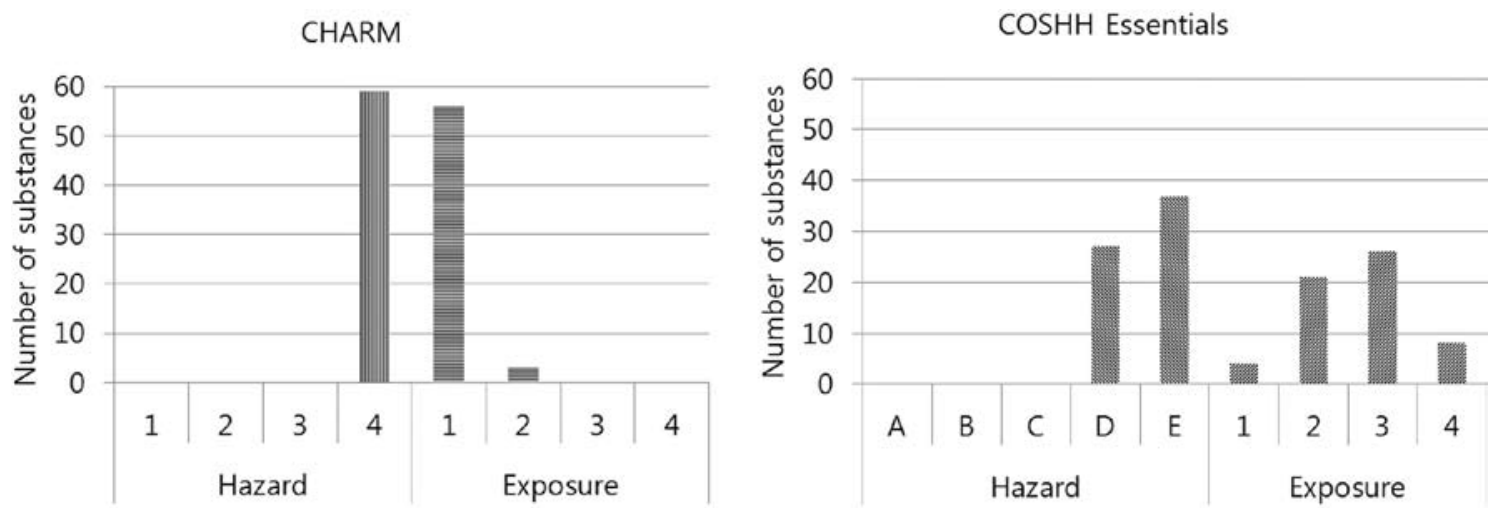

Fig. 2. Classification of hazard and exposure level according to Chemical Hazard Risk Management (CHARM) and Control of Substances Hazard to Health (COSHH) essentials.

working days $(300 \mathrm{~d} / \mathrm{yr})$. The overall daily usage for one workplace was calculated by dividing the total daily usage by the number of workplaces.

\section{Results}

The greatest difference between COSHH Essentials and CHARM is that they are applied differently, given the available information for the assessed substances. Furthermore, CHARM includes the results of working environment measurements. In order to establish the effects of these differences, risk assessments were conducted in the workplace for 59 CMR substances with known (measured) values using the CHARM manual $^{13)}$ and the COSHH Essentials guidelines ${ }^{14)}$. Physicochemical data for the substances were obtained from the Globally Harmonized System-Material Safety Data Sheets (GHS-MSDSs) via KOSHA ${ }^{22)}$.

Table 3 shows the risk level for 17 chemical substances as determined by CHARM and $\mathrm{COSHH}$ Essentials. Figure 2 shows the results of the hazard and exposure evaluations by CHARM and COSHH Essentials.

For CHARM, CMR materials were labeled as grade 4, which is the highest hazard grade in the assessment. In COSHH Essentials, the hazard assessment differed for the CMR materials. Carcinogenic or mutagenic 

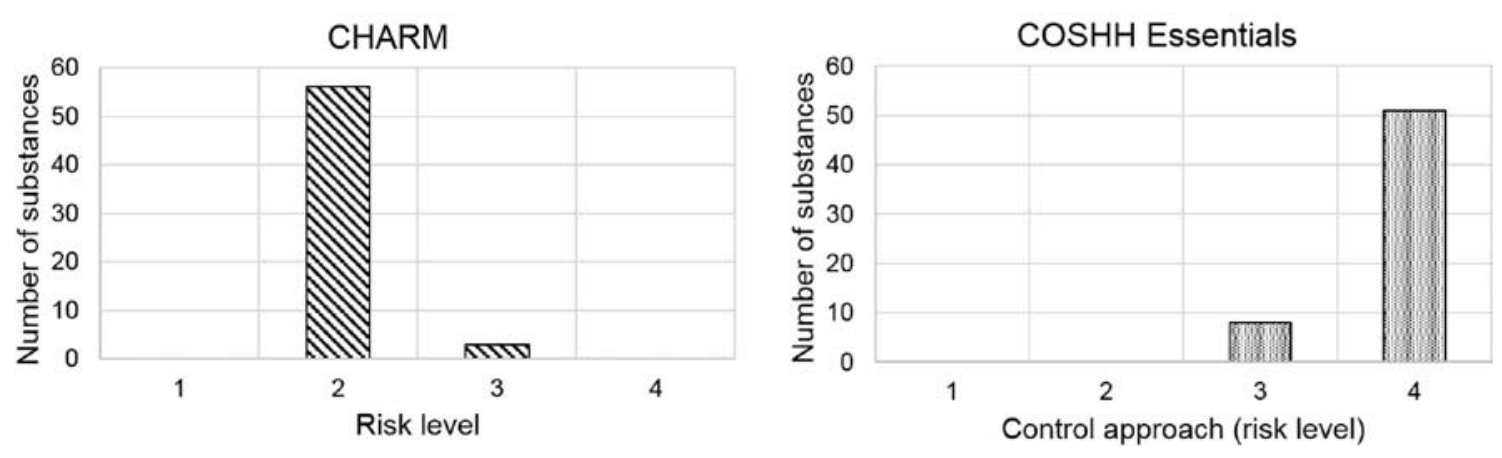

Fig. 3. Classification of risk level according to Chemical Hazard Risk Management (CHARM) and Control of Substances Hazard to Health (COSHH) essentials.

materials like Stoddard solvent, ethylene dichloride, dichloromethane, etc., were designated grades D or E. Materials toxic to reproduction like 1,2,3-trichloropropane, N,N-dimethylacetamide, methyl n-butyl ketone, methoxyethanol, etc., were labeled as grade D.

The results of the exposure assessment showed that most materials had grade 1 exposure values (less than $10 \%)^{13)}$ in the working environment measurements compared with the occupational exposure limit (TWA-OELs) ${ }^{23}$. Only 3 of the 59 CMR materials were found to be grade 2 (between 10 and 25\%) in the measurements. The numbers of CMR materials classified in each grade from 1 to 4 in the results of the exposure assessment by COSHH Essentials according to the usage and physical properties (fugacity/volatility) of each material were $4,21,26$, and 8 , respectively.

The results of the risk assessment showed that most chemicals evaluated using CHARM were assigned a lower risk (by 2 grades), whereas COSHH Essentials rated the risk level as grade 4 most frequently.

COSHH Essentials assessed the riskiness of grade E chemical substances, which have the highest hazard assessment results, as grade 4, even though the results from the exposure assessment were low (grades 1 or 2). However, CHARM assessed the riskiness of chemicals with low exposure grades (grades 1 or 2) as grade 2 or 3 , despite assigning a grade of 4 in the hazard assessment.

Figure 3 shows the comparisons of the risk level classification by CHARM and COSHH Essentials; the evaluations of the same CMR substances differed. The risk assessment was lower for CHARM than for COSHH Essentials. CHARM found low risk levels (grade 2) for 56 of the 59 substances. However, COSHH Essentials assessed higher risk levels (grade 4) for 51 of the 59 substances tested. Therefore, for the same CMR substances, CHARM assigned low risk levels in $95 \%$ of cases and COSHH Essentials assessed a high risk in $87 \%$ of cases. CHARM labeled 3 chemical substances at grade 3 , while COSHH Essentials found 8 chemical substances at that grade.

\section{Discussion}

Chemical substances are widely used, but when mishandled, they pose a hazard to the environment and can cause various occupational diseases ${ }^{24}$. In South Korea, carcinogens have become a social concern following growing incidents of lung cancer in workers exposed to asbestos and of leukemia in semiconductor factory workers ${ }^{25}$.

This study used CMR chemical substances to compare the features and distinctions of CHARM and COSHH Essentials for risk assessment of chemicals.

COSHH Essentials was developed in the UK as a convenient risk assessment method for chemicals used by small- and medium-sized enterprises ${ }^{26}$. CHARM, which is based on COSHH Essentials, is the system used in South Korea to assess risks in the workplace $^{13)}$. When evaluating CMR chemical substances, CHARM labels the most hazardous chemicals as a grade 4. However, COSHH Essentials assess hazards according to the R-phrases or $\mathrm{H}$-statements of the chemical substances. Hazard information is applied to the R-phrase or $\mathrm{H}$-statement by defining the $\mathrm{CHIP}^{16)}$ and CLP $^{17)}$ for each chemical. The hazard class of the chemical substances in this study were the same as those for the CHIP and CLP regulations ${ }^{27)}$.

Although COSHH Essentials and CHARM apply similar methods and standards, there were some differences in the methods with which the risk level was determined. For example, COSHH Essentials determines the risk level by classifying chemicals as solid or liquid, whereas CHARM does not consider the physical state of the chemical ${ }^{28)}$. Furthermore, the risk level in COSHH Essentials is assessed by a combination of the hazard and exposure levels as shown in Fig. 1, whereas CHARM calculates the 
risk by multiplying the hazard and exposure levels as shown in Table 1. In this study, the methods for determining risk levels were compared using banding as shown in Fig. 1; however, the only differences were in the procedure, since both methods use a combination of hazard and exposure levels.

The level of risk identified was much lower for CHARM than for COSHH Essentials; the hazard assessment was high for both, but the exposure assessment was low for both. CHARM determines the exposure level according to working environment measurements of the chemicals. COSHH Essentials assesses exposure levels using the physical properties and overall handling, and evaluates hazard through the $\mathrm{H}$-statements or R-phrases. It has been judged to be more conservative than CHARM.

The results of the working environment measurements of the 59 CMR chemical substances applied in this study showed that the workplace exposure levels were mostly lower than $10 \%$ compared with the occupational exposure limit (TWA-OELs). The percentage of workplaces in Korea where working environment measurements exceed the TWA-OELs is as low as $8 \%{ }^{29,30)}$. Furthermore, according to results of working environment measurements in car manufacturers, which uses a host of different chemicals, carcinogen like benzene were barely detected ${ }^{31,32)}$. For example, the working environment measurements for workplaces utilizing dichloromethane showed that $25.4 \%$ of workplaces had undetectable levels, $50.5 \%$ of workplaces had exposure levels of less than $10 \%$, and $17.8 \%$ of workplaces had exposure levels of less than $50 \%{ }^{33)}$.

For COSHH Essentials, CMR chemical substances are typically assessed as high risk because of the immediate allocation of a high hazard grade, regardless of the exposure level. However, for CHARM, when the exposure level is assessed as low, the risk is also considered low, despite the high hazard level of the CMR substances. Therefore, the exposure level influences the risk of the chemical more than the hazard level. Although a high-risk CMR substance may be used continuously, the risk management action will be assigned a risk level of 1 if the exposure level is low. Thus, there is a concern that a highly hazardous chemical substance will be assessed as low risk. As a result, it may be more effective to use CHARM for localized risk assessments for chemicals used in individual workplaces.

Acknowledgments: This study was supported by the Korea Occupational Safety and Health Agency and a research grant from Korea University. The authors gratefully acknowledge their support.
Conflict of interest: The authors declare that there are no conflicts of interest.

\section{References}

1) Park JK, Seo YW. A study on the improvement of the chemical accident response system. Korea Environment Institute; 2013. p. 1-56.

2) Choi MK, Choi DM. A study on the safety management measures efficient chemical substances. J Korea Saf Manag Sci 2013; 15: 37-50 (in Korean).

3) Park DY, Baek DM, Lee YS, et al. Development and introduction of an OSH regulatory framework based on risk assessment for Korean OSH regulation systems and policy. Occupational Safety and Health Research Institute; 2009. p. 1-175.

4) Zalk DM, Nelson DI. History and evolution of control banding: a review. J Occup Environ Hyg 2008; 5: 330-46.

5) Hay A. Controlling exposure to chemicals: a simple guide. Ann N.Y Acad Sci 2006; 1076: 790-9.

6) National Institute of Occupational Safety and Health. Qualitative risk characterization and management of occupational hazards: control banding (CB). DHHS (NIOSH); 2009. p. 1-32.

7) Fingerhut M. Global qualitative risk management (control banding) activities. Industrial Health 2008; 46: 305-7.

8) Jones RM, Nicas M. Evaluation of $\mathrm{COSHH}$ Essentials for vapor degreasing and bag filling operations. Ann Occup Hyg 2006; 50: 137-47.

9) Lee EG, James S, Russell B, Bowen, Martin H. Evaluation of COSHH Essentials model with a mixture of organic chemicals at a medium-sized paint producer. Ann Occup Hyg 2011; 55: 16-29.

10) Lee EG, James S, Russell B, Bowen, Martin H. Evaluation of COSHH Essentials: methylene chloride, isopropanol, and acetone exposures in a small printing plant. Ann Occup Hyg 2009; 53: 463-74.

11) Jones RM, Nicas M. Margins of safety provided by COSHH Essentials and ILO chemical control toolkit. Ann Occup Hyg 2006; 50: 149-56.

12) Lee EG, Kim SW, Feigley CE. Exposure models for the prior distribution in Bayesian decision analysis for occupational hygiene decision making. J Occup Environ Hyg 2013; 10: 97-108.

13) Korea Occupational Safety and Health Agency. Chemical risk assessment manual. KOSHA; 2012. p. 1-95.

14) Health and Safety Executive. The technical basis for COSHH essentials: Easy steps to control chemicals. [Online]. 2013 [cited 2013 Dec 04]; Available from: URL: http://www.coshh-essentials.org.uk/assets/live/ CETB.pdf

15) Maidment SC. Occupational hygiene considerations in the development of a structured approach to select chemical control strategies. Ann Occup Hyg 1998; 42: 391-400.

16) The chemicals (hazard information and packaging for supply) regulations. 716 (2009). 
17) Classification, labelling and packaging of substances and mixtures, amending and repealing regulations. 1272 (2008).

18) Russell RM, Maidment SC, Brooke IM, Topping MD. An introduction to a UK scheme to help small firms control health risks from chemicals. Ann Occup Hyg 1998; 42: 367-76.

19) Occupational Safety and Health Act. 10968 (2011).

20) Local rules on occupational safety and health standard. 77 (2013).

21) Korea Occupational Safety and Health Agency. 2009 Refund status reports national industrial work environment. Ministry of Employment and Labor; 2009.

22) Korea Occupational Safety and Health Agency. GHS/MSDS. [Online]. 2014 [cited 2014 Jan 17]; Available from: URL: http://www.kosha.or.kr/msds/ msdsMain.do?menuId=69

23) Topping M. Occupational exposure limits for chemicals. Occp Environ Med 2001; 58: 138-44.

24) Lee KS, Lee HJ, Lee JH. A study on the provide of CMR substances information for Threshold Limit Values (TLVs) chemicals in KMoEL. J Korean Soc Occup Environ Hyg 2012; 22: 82-90 (in Korean).

25) Lee KS, Lee HJ, Lee JH. A study on the criteria and supply status of information for managing carcinogens in domestic and foreign. J Korean Soc Occup Environ Hyg 2011; 21: 40-8 (in Korean).

26) Garrod AN, Evans PG, Davy CW. Risk management measures for chemicals: the "COSHH essentials" approach. J Expo Sci Environ Epidemiol 2007;
17(Suppl 1): 48-54.

27) Garrod ANI, Rajan-Sithamparanadarajah R. Developing COSHH Essentials: dermal exposure, personal protective equipment and first aid. Ann Occup Hyg 2003; 47: 577-88.

28) Brooke IM. A UK scheme to help small firms control health risks from chemicals: toxicological considerations. Ann Occup Hyg 1998; 42: 377-90.

29) Kim JH, Won JI. Analysis of overviews of working environment measurement and its results in Korean industry. Korean J Sanitation 1996; 11: 53-61 (in Korean)

30) Choi SJ. Assessment on Work Environment Monitoring Program in Korea. J Korean Soc Occup Environ Hyg 2008; 18: 282-92 (in Korean).

31) Oh DS, Lee YH. Study on analysis for working environmental measurement results of automobile industries. J Korean Soc Occup Environ Hyg 2004; 14: 233-42 (in Korean).

32) Park SJ, Lee WH, Lee K, Moon DH. A study on the status of working environmental by type of working processes in manufacturing industry of parts and accessories for motor vehicles and its engines. J Korean Soc Occup Environ Hyg 2005; 15: $90-103$ (in Korean).

33) Lee JH, Park DU, Hong SC, Ha KC. Construction of an exposure matrix using a risk assessment of industries and processes involving Dichloromethane. Korean J Environ Health Sci 2010; 36: 391-401 (in Korean). 